(C) The Author(s), 2021. Published by Cambridge University Press on behalf of The Nutrition Society. This is an Open Access article, distributed under the terms of the Creative Commons Attribution licence (http://creativecommons.org/licenses/by/4.0/), which permits unrestricted re-use, distribution, and reproduction in any medium, provided the original work is properly cited.

\title{
An index measuring adherence to New Zealand Infant Feeding Guidelines has convergent validity with maternal socio-demographic and health behaviours and with children's body size
}

\author{
Teresa G. Castro ${ }^{1,2 *}$, Sarah Gerritsen ${ }^{2,4}$, Juliana A. Teixeira ${ }^{3}$, Avinesh Pillai ${ }^{4}$, Dirce Maria L. Marchioni ${ }^{3}$, \\ Cameron C. Grant ${ }^{5}$, Susan M. B. Morton ${ }^{4}$ and Clare R. Wall ${ }^{1}$ \\ ${ }^{1}$ Nutrition Section, Faculty of Medical Sciences, University of Auckland, Auckland, New Zealand \\ ${ }^{2}$ Department of Epidemiology and Biostatistics, School of Population Health, University of Auckland, Auckland, New Zealand \\ ${ }^{3}$ Department of Nutrition, School of Public Health, University of Sao Paulo, Sao Paulo, Brazil \\ ${ }^{4}$ Centre for Longitudinal Research, School of Population Health, University of Auckland, Auckland, New Zealand \\ ${ }^{5}$ Department of Paediatrics: Child and Youth Health, School of Medicine, University of Auckland, Auckland, New Zealand
}

(Submitted 28 September 2020 - Final revision received 10 May 2021 - Accepted 16 May 2021 - First published online 2 July 2021)

\begin{abstract}
Using data from a nationally generalisable birth cohort, we aimed to: (i) describe the cohort's adherence to national evidence-based dietary guidelines using an Infant Feeding Index (IFI) and (ii) assess the IFI's convergent construct validity, by exploring associations with antenatal maternal socio-demographic and health behaviours and with child overweight/obesity and central adiposity at age 54 months. Data were from the Growing Up in New Zealand cohort ( $n$ 6343). The IFI scores ranged from zero to twelve points, with twelve representing full adherence to the guidelines. Overweight/obesity was defined by BMI-for-age (based on the WHO Growth Standards). Central adiposity was defined as waist-to-height ratio $>90$ th percentile. Associations were tested using multiple linear regression and Poisson regression with robust variance (risk ratios, $95 \%$ CI). Mean IFI score was $8 \cdot 2$ (sD 2.1). Maternal characteristics explained $29 \cdot 1 \%$ of variation in the IFI score. Maternal age, education and smoking had the strongest independent relationships with IFI scores. Compared with children in the highest IFI tertile, girls in the lowest and middle tertiles were more likely to be overweight/obese (1.46, 1.03, 2.06 and 1.56, 1.09, 2.23, respectively) and boys in the lowest tertile were more likely to have central adiposity $(1.53,1 \cdot 02,2 \cdot 30)$ at age 54 months. Most infants fell short of meeting national Infant Feeding Guidelines. The associations between IFI score and maternal characteristics, and children's overweight/obesity/central adiposity, were in the expected directions and confirm the IFI's convergent construct validity.
\end{abstract}

Keywords: Infant feeding: Dietary index: Dietary guidelines: Child obesity: Waist circumference

Dietary practices in early life represent a unique opportunity to tackle all forms of malnutrition. Promotion of breast-feeding and timely introduction, at around age 6 months, of nutritious, diverse foods in sufficient quantity and quality not only fosters children's growth and cognitive development but can also prevent overweight and obesity during early childhood, and obesity and diet-related diseases at adulthood ${ }^{(1,2)}$. In addition, the exposure of infants in the first months of life to varied tastes through breast milk and diverse and adequate foods facilitates the acceptance of nutritious food both at the time and in later life ${ }^{(1)}$.

Holistic assessment of infant feeding practices via diet quality indices (scores), rather than the assessment of individual nutrients or feeding practices, enables evaluation of how closely eating patterns align with evidence-based dietary guidelines ${ }^{(3)}$. This a priori approach allows analyses of the cumulative impact over time of the whole diet on health outcomes ${ }^{(5)}$. Consequently, there is interest in the use and assessment of dietary scores/ indices, as childhood food habits and behaviours can track overtime and predict diet-related diseases later in life ${ }^{(4)}$

However, in high-income countries, the use and application of diet indices in early life have not been fully explored. Reviews in this space indicate that further research is needed to better understand diet quality throughout early childhood and relationships with health-related outcomes ${ }^{(3)}$. There is also a lack of information on the validity of the developed indices, an aspect which is crucial for assessing the impact of adherence to dietary

Abbreviations: CAPI, computer-assisted personal interview; IFI, Infant Feeding Index; NZ, New Zealand; PA, physical activity; WC, waist circumference; WtHR, waist-to-height ratio.

* Corresponding author: Teresa Gontijo de Castro, email t.castro@auckland.ac.nz 
guidelines in early life on health outcomes through the life course $^{(5)}$

Ruel and Menon ${ }^{(6)}$ developed an Infant Feeding Index (IFI) for use in developing countries that has been used in a number of studies to describe adherence with international Infant Feeding Guidelines and to investigate the relationship of adherence with child anthropometric indicators ${ }^{(6-9)}$. However, this IFI did not adequately describe aspects of diet necessary to determine the relationship of infant feeding practices with the risk of obesity and non-communicable diseases in childhood ${ }^{(10)}$. A recent publication highlighted the need to redesign guidance for complementary feeding practices as one of the ten priority candidates for double-duty actions aimed at reducing the double burden of malnutrition globally ${ }^{(1)}$. In particular, there should be a greater emphasis on guidelines which specifically recommend to not feed young children foods, snacks and beverages high in energy, sugar, fat and salt ${ }^{(1)}$. In fact, the WHO and the United Nation Children's Fund have recently launched the revised indicators of infant and young child feeding practices, which advise against providing to this age group sweet drinks and unhealthy foods, characterised by being energy-dense, nutrient poor and high in salt, sugar, saturated and/or trans-fatty acids ${ }^{(11)}$.

To our knowledge, only one previous study, using data from the Avon Longitudinal Study of Parents and Children, has created and validated an IFI that has broad application to high-income countries, based on guidelines from Australia, New Zealand (NZ), North America and the $\mathrm{UK}^{(12,13)}$. However, part of the indicator components that constitute this index ${ }^{(12,13)}$ is not recommended practice in $\mathrm{NZ}^{(2)}$, such as feeding on demand, timing of lumpy foods introduction and exposure to commercial infant foods.

Recently an $\mathrm{IFI}^{(14)}$ based on the NZ Food and Nutrition Guidelines for Healthy Infants and Toddlers ${ }^{(2)}$, referred from here as the Infant Feeding Guidelines, was developed using data from the Growing Up in New Zealand study, a contemporary nationally generalisable birth cohort ${ }^{(15)}$. Face and content validity of the IFI were assumed, as it was developed based on the academic and policymaker's expertise and practice ${ }^{(14,16)}$. Full and complete assessment of criterion validity of diet quality indices is not possible as there are currently no gold standards for diet quality ${ }^{(17)}$. In paediatric populations, the assessment of the convergent construct validity of a diet quality index represents an important method for examining the usefulness of the index for a particular setting ${ }^{(3)}$.

In the present study, we aimed to: (i) describe the adherence of the Growing Up in New Zealand cohort to the nationally recommended infant feeding practices using the IFI and (ii) assess the IFI's convergent validity, by exploring its associations with antenatal maternal socio-demographic and health behaviours and with child overweight/obesity and central adiposity at age 54 months.

\section{Methods}

Study population, data collection waves and ethical approval

This investigation was conducted within the contemporary NZ birth cohort study, Growing Up in New Zealand, which enrolled
6822 pregnant women and their 6853 children who survived to age 6 weeks ${ }^{(15)}$. Eligibility was defined by residency within a region of NZ chosen for its ethnic and socio-economic diversity and having an estimated delivery date between 25 April 2009 and 25 March 2010. The cohort at birth was broadly generalisable by ethnicity and socio-economic position to all NZ births from 2007 to 2010. This study was conducted according to the guidelines laid down in the Declaration of Helsinki, and all procedures involving human subjects were approved by the the Ministry of Health Northern Y Regional Ethics Committee (NTY/08/06/055). Written informed consent was obtained from all mothers/caregivers ${ }^{(15)}$.

We used information from five data collection waves, completed antenatally and when the cohort children were approximately 6 weeks, 9,31 and 54 months old. The antenatal interview was completed by all 6822 enrolled women. Of the 6853 children enrolled in the cohort, the respective proportions of children for whom the 6-week, 9-, 31- and 54-month interviews were completed were 99.9, 94.5, $92 \cdot 3$ and $89 \cdot 8 \%{ }^{(18)}$.

Data on maternal socio-demographic and health behaviour characteristics were obtained from the antenatal face-to-face computer-assisted personal interview (CAPI), collected in 2008/2009. Infants' perinatal information (sex, fetal count, birth and gestational age) and infants' feeding status in the first few weeks of life were obtained from the 6-week computer-assisted telephone interview. Information on infant dietary intake and age of food introduction were obtained from the 9-month CAPI. Variables describing initiation and duration of any and exclusive breast-feeding were derived from the 6-week computer-assisted telephone interview, 9-month CAPI and the 31-month computer-assisted telephone interview. The 54-month CAPI provided information on children's screen use and anthropometric measurements of weight (W), height (H) and waist circumference (WC).

The sample for this study was limited to cohort children aged 6-12 months, when the 9-month CAPI took place ( $n$ 6343); $97.9 \%$ of the infants for whom the 9-month CAPI was completed. Analyses examining the associations between the infants' scoring in the IFI and antenatal maternal characteristics and between the IFI scoring and the child's anthropometric outcomes at 54-month CAPI excluded twins/triplets, children with a birth weight less than $2500 \mathrm{~g}$ or gestational age less than 37 weeks age. Twins/triplets were excluded so that only independent observations were included. Children with a birth weight less than $2500 \mathrm{~g}$ or gestational age less than 37 weeks age were excluded because the Infant Feeding Guidelines ${ }^{(2)}$ may not be appropriate for preterm or low-birth weight babies, many of whom would be following tailored clinical nutrition guidelines.

The analyses examining associations of the infants' IFI score with child BMI-for-age and waist-to-height ratio (WtHR) were restricted to children for whom both the 9- and 54-month CAPI were completed, and for whom information on $\mathrm{W}$ and $\mathrm{H}$ (for BMI-for-age) and on WC and H (for WtHR) was collected at the 54-month CAPI (online Supplementary Fig. S1).

\section{Adherence to national recommended infant feeding practices}

The IFI was previously developed ${ }^{(14)}$ based on the Infant Feeding Guidelines $^{(2)}$ that were current when the 9-month CAPI took place. 
The guidelines were based on the international evidence about the types of food and nutrition that supports health and development for this age group, interpreted for the NZ population ${ }^{(2)}$. The indicators that compose the IFI were created using statements in the Infant Feeding Guidelines ${ }^{(2)}$ that were applicable to infants $<12$-months-old and able to be measured with the Growing Up in New Zealand data. The IFI contains indicators of breastfeeding, dietary intake and age of food introduction ${ }^{(14)}$. At the 9-month CAPI, information on dietary intake and age of food introduction were collected using a semi-quantitative FFQ. The FFQ was adapted from the tool used by the Southampton Women's Survey study ${ }^{(19)}$ with mothers asked to report the age of introduction and baby's current frequency of intake of twenty-five food items, including infant milk formula or milk other than breast milk $^{(20)}$. Mothers were also asked if their infants ever tried any infant formula or milk other than breast milk and the types of milk and infant formula. The FFQ's food list was designed by an experienced academic paediatric dietitian, who selected items based on the Infant Feeding Guidelines ${ }^{(2)}$ and foods and beverages commonly fed to NZ infants ${ }^{(21)}$. The selection and scoring of the indicators to compose the IFI were determined by consensus agreement between five academics with nutritional expertise, one academic general paediatrician and the Nutrition Policy team at the NZ Ministry of Health.

The IFI was further refined with developers. The IFI score represents the sum of the twelve infant feeding indicators (with maximum score of one point each, twelve in total), where higher score indicates greater adherence to the Infant Feeding Guidelines. Details on the indicators' link to the statements of the Infant Feeding Guidelines ${ }^{(2)}$ and on their scoring are provided in Table 1.

\section{Antenatal maternal socio-demographic and health behaviour characteristics}

Antenatal maternal socio-demographic and health behaviour variables that could potentially affect adherence with recommended infant feeding practices were examined. The sociodemographic variables assessed were parity; pregnancy planning; level of education completed; age; length of migration to NZ; maternal self-prioritised ethnicity level 1 and the NZDep2006 Index of Deprivation, which is a well-validated small area measure of neighbourhood deprivation ${ }^{(22)}$. In NZ, ethnicity is self-identified, and individuals can identify with multiple ethnicities. Based on this identification, the selfprioritised ethnicity level 1 is an ethnic group classification based on the Statistics NZ ${ }^{(23)}$ prioritisation of the allocation of individuals to one ethnic group. Thus, the ethnic grouping used in this study was as follows: (1) European, (2) Māori, (3) Pacific People, (4) Asian, (5) Middle Eastern, Latin American and African and (6) other. The categories Middle Eastern, Latin American and African and other were combined for analysis purposes. The NZDep06 combines nine socio-economic characteristics from the 2006 census data collected at aggregations of approximately 100 people and assigned to individual households based on geo-coded address data ${ }^{(22)}$.

The antenatal maternal health behaviour variables examined were adherence to nutrition guidelines in pregnancy; pre-pregnancy BMI; smoking patterns before/during pregnancy and physical activity (PA) before/during pregnancy. The assessment of daily intakes during pregnancy of: vegetables and fruit; breads and cereals; milk and milk products; and lean meat, meat and alternatives and eggs was based in the number of servings consumed and comparing to the national recommendations for pregnant women when the antenatal interview took place ${ }^{(24)}$. Pre-pregnancy BMI was calculated based on self-reported weight and height and was classified according to the WHO cut-offs ${ }^{(25)}$. Smoking patterns pre/during pregnancy were categorised as continued smoking, stopped smoking and non-smokers. PA during pregnancy was estimated using the International Physical Activity Questionnaire. Participants were asked about intensity (moderate or vigorous), duration $(<30$, $30-60,>60 \mathrm{~min}$ ) and frequency (days per week) of activity ${ }^{(26)}$. Women who engaged in moderate PA for at least $30 \mathrm{~min}$ for at least 5 out of $7 \mathrm{~d}$, or vigorous PA for at least $30 \mathrm{~min}$ on at least 2 out of $7 \mathrm{~d}$ were classified as participating in moderate/vigorous activity. The PA categories examined were no moderate/ vigorous PA before or during pregnancy, moderate/vigorous PA before and during pregnancy, and moderate/vigorous PA only before or during pregnancy.

\section{Children's BMI-for-age, waist-to-height ratio and screen use at the 54-month interview}

Each child's exact age (in months) at the 54-month CAPI was calculated by the difference from the date of the interview and the child's date of birth. Measurements of each child's W, $\mathrm{H}$ and $\mathrm{WC}$ were collected by trained interviewers according to the international protocols (for $\mathrm{W}$ and $\mathrm{H})^{(25)}$ and national protocols (for WC) ${ }^{(27)}$. W measurements in kg were taken using Tanita Digital scale (Model HD-351), with a capacity of $200 \mathrm{~kg}$ and precision of $0 \cdot 1 \mathrm{~kg}$. H measurements in cm were taken using a laser stadiometer (Precaster CA600), with capacity of $50 \mathrm{~m}$ and precision of $0.2 \mathrm{~cm}$. WC measurements were taken, using a standard flexible plastic measuring tape that is used for dressmaking. For measuring, W and $\mathrm{H}$ children wore light clothes, had shoes off and no hair ornaments. WC was measured over light clothing at the midpoint between the lower margin of the least palpable rib and the top of the iliac crest. Measurements of W, H and WC were taken in duplicate and if the differences between measurements were greater than $0.5 \mathrm{~kg}, 1 \mathrm{~cm}$ and $1 \mathrm{~cm}$ for W, $\mathrm{H}$ and $\mathrm{WC}$, respectively, a third measurement was collected. The final measurements of $\mathrm{W}, \mathrm{H}$ and $\mathrm{WC}$ were defined as the average value of two measurements or the average of the two closest values.

Children's BMI-for-age values were calculated according to the WHO 2006 Growth Standards ${ }^{(28)}$. Children with BMI-for-age greater than $+2 z$-scores were classified as being overweight/obese. Children with BMI-for-age values greater than $+5 z$-scores were considered as BMI-for-age outlier values $^{(28)}$. The WtHR was calculated by dividing the WC $(\mathrm{cm})$ by the $\mathrm{H}(\mathrm{cm})$. The cut-off of the 90th percentile was used to define central adiposity.

Mothers or caregivers reported the average minutes on a usual weekday their child watched television (including freeto-air, online and pay television or DVD either on television or other media) and used electronic media (e.g. computer or 
Table 1. Indicators included in and the scoring of the infant feeding index and links of each indicator with the NZ Infant Feeding Guidelines

\begin{tabular}{|c|c|c|c|c|}
\hline \multirow{2}{*}{$\begin{array}{l}\text { Indicator } \\
\text { Duration of any breast-feeding } \\
\text { Dose-response score: gradual increase to } \\
12 \text { months or beyond of duration }\end{array}$} & \multicolumn{2}{|c|}{ Categories/scoring } & $\begin{array}{c}\begin{array}{c}\text { Maximum } \\
\text { score }\end{array} \\
1.0\end{array}$ & $\begin{array}{l}\text { Linking statement in the NZ Infant Feeding Guidelines }{ }^{(12)} \\
\text { Statement 3: When your baby is ready, introduce him or her }\end{array}$ \\
\hline & $\begin{array}{l}\text { None } \\
\leq 1 \text { month* } \\
2 \text { months } \\
3 \text { months } \\
4 \text { months } \\
5 \text { months } \\
6 \text { months } \\
7 \text { months } \\
8 \text { months } \\
9 \text { months } \\
10 \text { months } \\
11 \text { months } \\
\geq 12 \text { months }\end{array}$ & \begin{tabular}{l}
\multicolumn{1}{c}{0} \\
0.083 \\
0.166 \\
0.249 \\
0.332 \\
0.415 \\
0.498 \\
0.581 \\
0.664 \\
0.747 \\
0.830 \\
0.913 \\
1.0
\end{tabular} & & $\begin{array}{l}\text { Statement 3: When your baby is ready, introduce him or her } \\
\text { to appropriate complementary foods and continue to } \\
\text { breastfeed until they are at least one year of age, or } \\
\text { beyond }\end{array}$ \\
\hline $\begin{array}{l}\text { Duration of exclusive breast-feeding } \\
\text { Dose-response score with } U \text {-shape: } \\
\text { gradual increase to } 6 \text { months and } \\
\text { decrease from } 7 \text { months of duration }\end{array}$ & $\begin{array}{l}\text { None } \\
\leq 1 \text { month } \\
2 \text { months } \\
3 \text { months } \\
4 \text { months } \\
5-6 \text { months } \\
7 \text { months } \\
8 \text { months } \\
9 \text { months }\end{array}$ & $\begin{array}{l}0 \\
0.2 \\
0.4 \\
0.6 \\
0.8 \\
1.0 \\
0.8 \\
0.6 \\
0.4\end{array}$ & 1.0 & $\begin{array}{l}\text { Statement 2: Exclusively breastfeed your baby until your } \\
\text { baby is ready for and needs extra food - this will be at } \\
\text { around } 6 \text { months of age }\end{array}$ \\
\hline Age of introduction of solids & $\begin{array}{l}\leq 4 \text { months } \\
5-6 \text { months } \\
\geq 7 \text { months }\end{array}$ & $\begin{array}{r}0 \\
1 \cdot 0 \\
0\end{array}$ & 1.0 & $\begin{array}{l}\text { Statement 3: When your baby is ready, introduce him or her } \\
\text { to appropriate complementary foods and continue to } \\
\text { breastfeed until they are at least one year of age, } \\
\text { or beyond }\end{array}$ \\
\hline Eating across the four food groups daily & $\begin{array}{l}\text { No } \\
\text { Yes }\end{array}$ & $\begin{array}{r}0 \\
1.0\end{array}$ & 1.0 & $\begin{array}{l}\text { Statement } 4 \text { : Increase the texture, variety, flavour and amount } \\
\text { of food offered so that your baby receives a complementary } \\
\text { intake of nutrients, especially Fe and vitamin } \mathrm{C} \text {, and is } \\
\text { eating more family foods by } 1 \text { year of age }\end{array}$ \\
\hline Vegetable intake frequency & $\begin{array}{l}\text { None or less than } \\
\quad \text { daily } \\
\geq 1 \text { and }<2 \text { times/ } \\
\text { daily } \\
\geq 2 \text { times/daily }\end{array}$ & $\begin{array}{r}0 \\
0.5 \\
1.0\end{array}$ & 1.0 & $\begin{array}{l}\text { Statement 4: Increase the texture, variety, flavour and amount } \\
\text { of food offered so that your baby receives a complementary } \\
\text { intake of nutrients, especially Fe and vitamin C, and is } \\
\text { eating more family foods by } 1 \text { year of age }\end{array}$ \\
\hline Fruit intake frequency & $\begin{array}{l}\text { None or less than } \\
\quad \text { daily } \\
\geq 1 \text { and }<2 \text { times/ } \\
\text { daily } \\
\geq 2 \text { times/daily }\end{array}$ & $\begin{array}{r}0 \\
0.5 \\
1.0\end{array}$ & 1.0 & $\begin{array}{l}\text { Statement } 4 \text { : Increase the texture, variety, flavour and amount } \\
\text { of food offered so that your baby receives a complementary } \\
\text { intake of nutrients, especially Fe and vitamin } \mathrm{C} \text {, and is } \\
\text { eating more family foods by } 1 \text { year of age }\end{array}$ \\
\hline Fe-rich foods intake frequency & $\begin{array}{l}\text { None or less than } \\
\text { daily } \\
\geq 1 \text { time/daily }\end{array}$ & $\begin{array}{r}0 \\
1.0\end{array}$ & 1.0 & $\begin{array}{l}\text { Statement } 4 \text { : Increase the texture, variety, flavour and amount } \\
\text { of food offered so that your baby receives a complementary } \\
\text { intake of nutrients, especially Fe and vitamin } \mathrm{C} \text {, and is } \\
\text { eating more family foods by } 1 \text { year of age }\end{array}$ \\
\hline $\begin{array}{l}\text { Inappropriate milk drinks tried prior to } \\
\text { the 9-month interview }\end{array}$ & $\begin{array}{l}\text { No } \\
\text { Yes }\end{array}$ & $\begin{array}{r}1.0 \\
0\end{array}$ & 1.0 & $\begin{array}{l}\text { Statement 3: When your baby is ready, introduce him or her } \\
\text { to appropriate complementary foods and continue to } \\
\text { breastfeed until they are at least one year of age, } \\
\text { or beyond } \\
\text { Statement } 6 \text { : If your baby is not fed breast milk, then use an } \\
\text { infant formula as the milk source until your baby is } 1 \text { year } \\
\text { of age }\end{array}$ \\
\hline $\begin{array}{l}\text { Inappropriate other drinks tried prior to the } \\
\text { 9-month interview }\end{array}$ & $\begin{array}{l}\text { No } \\
\text { Yes }\end{array}$ & $\begin{array}{r}1.0 \\
0\end{array}$ & 1.0 & $\begin{array}{l}\text { Statement 10: Do not give your infant or toddler alcohol, } \\
\text { coffee, cordials, juice, soft drink, tea (including herbal } \\
\text { drinks) and drinks containing caffeine }\end{array}$ \\
\hline $\begin{array}{l}\text { Inappropriate foods tried prior to the } \\
\text { 9-month interview }\end{array}$ & $\begin{array}{l}\text { No } \\
\text { Yes }\end{array}$ & $\begin{array}{r}1.0 \\
0\end{array}$ & $1 \cdot 0$ & $\begin{array}{l}\text { Statement 5: For your baby, prepare or choose pre-prepared } \\
\text { complementary foods with no added fat, salt, sugar, honey } \\
\text { or other sweeteners }\end{array}$ \\
\hline Addition of salt to baby's meals & $\begin{array}{l}\text { Yes (or sometimes) } \\
\text { No }\end{array}$ & $\begin{array}{r}0 \\
1.0\end{array}$ & 1.0 & $\begin{array}{l}\text { Statement 5: For your baby, prepare or choose pre-prepared } \\
\text { complementary foods with no added fat, salt, sugar, honey } \\
\text { or other sweeteners }\end{array}$ \\
\hline Addition of sugar to baby's meals & $\begin{array}{l}\text { Yes (or sometimes) } \\
\text { No }\end{array}$ & $\begin{array}{r}0 \\
1.0\end{array}$ & 1.0 & $\begin{array}{l}\text { Statement 5: For your baby, prepare or choose pre-prepared } \\
\text { complementary foods with no added fat, salt, sugar, honey } \\
\text { or other sweeteners }\end{array}$ \\
\hline Total points in the Infant Feeding Index & & & $12 \cdot 0$ & \\
\hline
\end{tabular}

${ }^{*}$ Category includes infants who were breastfed for $14 \mathrm{~d}$ or less. 
laptop, including children's computer systems such as Leapfrog, iPads, tablets, smart phones and any electronic gaming devices). Children's total screen use ( $\mathrm{min} / \mathrm{d}$ ) was calculated by summing the average time spent in these activities. Recommended average screen use was defined by the international screen use guidelines $^{(30)}$ as $<60 \mathrm{~min} / \mathrm{d}$.

\section{Statistical analysis}

Descriptive statistics were reported using means and standard deviations, medians and value range for continuous variables and proportions for categorical variables. Proportions and means were compared, respectively, using the $\chi^{2}$ test and Student $t$ tests for independent samples.

Associations between the IFI score (dependent variable) and antenatal maternal socio-demographic and health behaviour characteristics (independent variables) were examined in unadjusted and adjusted linear regression models with associations described using $\beta$-coefficients and $95 \%$ confidence intervals (95\% CI). Univariate associations with $P<0.15$ were used to identify variables to be tested in the multiple variable linear regression model, following a forward stepwise approach. Covariates were retained in the adjusted models if associations with the outcome had $P<0.05$ or changed the magnitude of the $\beta$-coefficient by $10 \%$ or more.

Associations between the children overweight/obesity and central obesity at 54 months (dependent variables) and the IFI score (independent variable) were examined in unadjusted and adjusted Poisson regression models with robust variance with associations described using risk ratios and 95\% CI. For these analyses, infants were categorised into IFI score tertiles, according to their ranking within the complete sample and according to their ranking within sexes (for sex-specific analyses). In this study, we opted for using Poisson regression with robust variance as an alternative to the odds ratio (OR), as OR can overestimate prevalence ratios and this overestimation increases as the prevalence of the outcome increases ${ }^{(30,31)}$. To select the independent variables to be tested in these models, an a priori causal model was used based on the published literature $^{(12,13,32-38)}$. This a priori model assumes that antenatal maternal socio-demographic and health behaviour variables influence both the IFI score and childhood adiposity and, therefore, need to be adjusted for in the models. In addition, the anthropometric outcomes measured at the 54-month CAPI were also adjusted for child sex, exact age and screen time use at that time point. Univariate associations with $P<0.15$ were used to identify the independent variables to be tested in the multiple regression models, following a forward stepwise approach. Covariates were retained in the final models if associations with the outcomes had $P<0.05$ or changed the magnitude of risk ratios by $10 \%$ or more. Models with BMI-for-age as outcome excluded the children with BMI-for-age outliers ${ }^{(28)}$. Then, sensitivity analyses were performed to check whether the associations between the IFI score and children's BMI-for-age altered if the children with BMI-for-age outlier values were included in the model. Where relevant, analyses were also stratified by sex. All analyses were performed using SPSS software (version 25, IBM SPSS Statistics).

\section{Results}

\section{Study population}

Table 2 shows the distribution of the infants according to their perinatal characteristics, demographics, screen time use and anthropometric outcomes and their mothers' sociodemographic and health behaviour characteristics. Except for low-birth weight and BMI-for-age, there were no statistically significant differences in the distribution of the variables by sex. The majority of the infants ( $n 6120,96.5 \%)$ were aged between 8 and 12 months when the 9-month CAPI was completed. Approximately half of the children were 48.0-53.9 months-old when the 54-month CAPI was completed. In relation to girls, a larger proportion of boys were classified as overweight/obese $(15.7 \% v .12 \cdot 0 \%, P<0.001)$ (Table 2). The mean of WtHR in the population was 0.509 (sD 0.038), with no significant statistical differences in means between boys and girls $(t=0 \cdot 226 ; P=0 \cdot 821)$ (data not shown).

\section{Adherence to the Infant Feeding Guidelines}

Overall, less than $2.0 \%$ of the infants had complete adherence to the Infant Feeding Guidelines ${ }^{(12)}, 15.9 \%$ scored less than six points and $23.3 \%$ scored ten points or more in the IFI (Fig. 1(a)). The IFI score was normally distributed and its mean was 8.20 (sD 2.1) points, with a minimum score of 0.283 points. When comparing boys and girls, there were no statistically significant differences in the IFI mean score $(t=0.246$; $P=0.729)$ or IFI tertile distribution $\left(\chi^{2}-=0.017 ; P=0.991\right)$. When comparing the level of adherence to each of the indicators of the IFI in boys $v$. girls, adherence to eating the four core food groups $(57.8 \% v .55 \%)$, daily intake of fruit $(38.2 \% v .35 \cdot 8 \%)$ and vegetables $(33.9 \% v .31 .5 \%)$ were higher among boys than girls. Girls had higher adherence to the indicators of duration of exclusive breast-feeding (34.9\% v. 30.8\%), age of complementary food introduction $(58.4 \% v .55 .7 \%)$ and not introducing inappropriate milks $(96.8 \% v .95 \cdot 6 \%)$ and other drinks $(63.2 \% v$. 60.6\%) (Fig. 1(b)).

\section{Associations between the infants' Infant Feeding Index score with maternal socio-demographic and health behaviour characteristics}

The unadjusted associations between the infants' IFI score and the maternal socio-demographic and health behaviour characteristics are presented in online Supplementary Table S1. In the fully adjusted model, compared with the reference categories, infants who scored lower in the IFI were more likely to be: not first born, from an unplanned pregnancy and living in the most deprived quintile of neighbourhoods. They were more likely to have mothers with lower levels of education, who were of ethnicities other than European, younger than 35 years of age, who smoked before and/or during pregnancy, were overweight pre-pregnancy, who did not adhere to the guidelines of intake of fruit/vegetables and milk/milk products in pregnancy, who did adhere to the guidelines of intake of breads and cereals in pregnancy or who migrated to NZ less than 4 years prior to the antenatal interview. Almost $30 \%$ of the variation of the IFI score was explained by maternal antenatal socio-demographic 
Table 2. Antenatal maternal socio-demographic and health behaviour characteristics; perinatal characteristics and age of the cohort when the 9-month interview was completed; and BMI-for-age, waist-circumference-to-height ratio, screen time usage and demographics of the cohort as measured at the 54-month interview (all cohort and by sex)

(Numbers and percentages)

\begin{tabular}{|c|c|c|c|c|c|c|c|}
\hline Variables & \multicolumn{2}{|c|}{$\begin{array}{c}\text { All cohort } \\
n(\text { column \%) }\end{array}$} & \multicolumn{2}{|c|}{$\begin{array}{c}\text { Girls } \\
n \text { (column \%) }\end{array}$} & \multicolumn{2}{|c|}{$\begin{array}{c}\text { Boys } \\
n \text { (column \%) }\end{array}$} & \multirow[t]{2}{*}{$P^{\star}$} \\
\hline \multicolumn{7}{|c|}{ Mothers antenatal socio-demographic and health behaviour characteristics ( $n$ 6343) $\dagger$} & \\
\hline \multicolumn{8}{|l|}{ Pregnancy planning } \\
\hline Yes & 3897 & $61 \cdot 8$ & 1907 & $62 \cdot 6$ & 1990 & $61 \cdot 0$ & $0 \cdot 19$ \\
\hline No & 2407 & $38 \cdot 2$ & 1137 & $37 \cdot 4$ & 1270 & $39 \cdot 0$ & \\
\hline \multicolumn{8}{|l|}{ Highest level of education } \\
\hline Higher than bachelor's degree & 1021 & $16 \cdot 1$ & 488 & $16 \cdot 0$ & 533 & $16 \cdot 3$ & \\
\hline Bachelor's degree & 1478 & 23.4 & 705 & $23 \cdot 1$ & 773 & $23 \cdot 7$ & 0.59 \\
\hline Diploma/trade cert/NCEA 5-6 & 1939 & 30.7 & 937 & 30.7 & 1002 & $30 \cdot 7$ & \\
\hline Secondary school/NCEA 1-4 & 1471 & $23 \cdot 3$ & 734 & $24 \cdot 1$ & 737 & $22 \cdot 6$ & \\
\hline No secondary school qualification & 408 & 6.5 & 187 & $6 \cdot 1$ & 221 & $6 \cdot 8$ & \\
\hline \multicolumn{8}{|l|}{ Self-prioritised ethnicity } \\
\hline European & 3511 & $55 \cdot 6$ & 1720 & $56 \cdot 3$ & 1791 & 54.9 & \\
\hline Māori & 838 & $13 \cdot 3$ & 395 & 12.9 & 443 & $13 \cdot 6$ & 0.84 \\
\hline Pacific & 855 & $13 \cdot 5$ & 407 & $13 \cdot 3$ & 448 & $13 \cdot 7$ & \\
\hline Asian & 904 & $14 \cdot 3$ & 434 & $14 \cdot 2$ & 470 & $14 \cdot 4$ & \\
\hline MELAA and other & 212 & 3.4 & 100 & $3 \cdot 3$ & 112 & 3.4 & \\
\hline \multicolumn{8}{|l|}{ Neighbourhood deprivation (NZDep2006 quintiles) $\ddagger$} \\
\hline 1-2 least deprived & 1044 & $16 \cdot 5$ & 525 & $17 \cdot 2$ & 519 & $15 \cdot 9$ & \\
\hline $3-4$ & 1199 & $18 \cdot 9$ & 581 & $19 \cdot 0$ & 618 & $18 \cdot 9$ & 0.64 \\
\hline $5-6$ & 1103 & $17 \cdot 4$ & 519 & $17 \cdot 0$ & 584 & $17 \cdot 9$ & \\
\hline $7-8$ & 1334 & $21 \cdot 1$ & 637 & $20 \cdot 8$ & 697 & $21 \cdot 3$ & \\
\hline 9-10 most deprived & 1651 & $26 \cdot 1$ & 798 & $26 \cdot 1$ & 853 & $26 \cdot 1$ & \\
\hline \multicolumn{8}{|l|}{ Age group (years) } \\
\hline$\geq 35$ years & 1637 & $25 \cdot 8$ & 772 & $25 \cdot 2$ & 865 & $26 \cdot 4$ & \\
\hline 20-34 years & 4419 & $69 \cdot 8$ & 2154 & $70 \cdot 4$ & 2265 & $69 \cdot 2$ & 0.55 \\
\hline$<20$ years & 277 & 4.4 & 134 & 4.4 & 143 & 4.4 & \\
\hline \multicolumn{8}{|l|}{ Parity } \\
\hline First born & 2659 & $42 \cdot 0$ & 1280 & 41.9 & 1379 & $42 \cdot 2$ & 0.79 \\
\hline Subsequent & 3668 & $58 \cdot 0$ & 1778 & $58 \cdot 1$ & 1890 & $57 \cdot 8$ & \\
\hline \multicolumn{8}{|l|}{ Length of time living in NZ (years) } \\
\hline Born in NZ & 4141 & $65 \cdot 3$ & 2012 & $65 \cdot 7$ & 2129 & 64.9 & 0.81 \\
\hline Living in NZ for $>4$ years & 1445 & $22 \cdot 8$ & 688 & $22 \cdot 5$ & 757 & $23 \cdot 1$ & \\
\hline Living in $\mathrm{NZ}$ for $\leq 4$ years & 757 & 11.9 & 364 & 11.9 & 393 & $12 \cdot 0$ & \\
\hline Pre-pregnancy BMI (kg/m²) & & & & & & & \\
\hline$<25.0$ & 3363 & 58.9 & 1597 & $58 \cdot 8$ & 1715 & $59 \cdot 4$ & \\
\hline $25-29.99$ & 1299 & $22 \cdot 8$ & 642 & 23.6 & 627 & $21 \cdot 7$ & $0 \cdot 18$ \\
\hline$\geq 30 \cdot 0$ & 1045 & $18 \cdot 3$ & 479 & $17 \cdot 6$ & 544 & $18 \cdot 8$ & \\
\hline Adherence to nutrition guidelines in pregnancy met for & & & & & & & \\
\hline Fruit and vegetables & 1442 & $24 \cdot 9$ & 683 & $24 \cdot 2$ & 759 & 25.5 & 0.27 \\
\hline Breads and cereals & 1547 & $26 \cdot 7$ & 744 & $26 \cdot 4$ & 803 & $26 \cdot 9$ & 0.62 \\
\hline Milk and milk products & 3376 & $58 \cdot 2$ & 1650 & $58 \cdot 5$ & 1726 & $57 \cdot 9$ & 0.66 \\
\hline Meats and alternatives and eggs & 1265 & $21 \cdot 8$ & 601 & $21 \cdot 3$ & 664 & $22 \cdot 3$ & 0.37 \\
\hline Smoking before and during pregnancy & & & & & & & \\
\hline Non-smokers before and during pregnancy & 4658 & $80 \cdot 5$ & 2291 & 81.6 & 2367 & $79 \cdot 6$ & $0 \cdot 15$ \\
\hline Stopped smoking during pregnancy & 560 & $9 \cdot 7$ & 254 & $9 \cdot 0$ & 306 & $10 \cdot 3$ & \\
\hline Smokers before and during pregnancy & 565 & 9.8 & 264 & $9 \cdot 4$ & 301 & $10 \cdot 1$ & \\
\hline Physical activity before and during pregnancy§ & & & & & & & \\
\hline Moderate/vigorous physical activity before and during pregnancy & 1951 & $33 \cdot 6$ & 945 & 33.5 & 1006 & $33 \cdot 8$ & 0.97 \\
\hline Moderate/vigorous physical activity only before or during pregnancy & 1536 & $26 \cdot 5$ & 747 & $26 \cdot 5$ & 789 & $26 \cdot 5$ & \\
\hline No moderate/vigorous physical activity before and during pregnancy & 2314 & 39.9 & 1129 & $40 \cdot 0$ & 1185 & $39 \cdot 8$ & \\
\hline Cohort children's perinatal characteristics & demogr & ics at th & nonth $\mathrm{i}$ & view $(n$ & & & \\
\hline Singleton/twins/triplets & & & & & & & \\
\hline Singletons & 6179 & $97 \cdot 4$ & 2973 & $97 \cdot 0$ & 3206 & $97 \cdot 8$ & 0.09 \\
\hline Twins/triplets & 164 & 2.6 & 89 & 2.9 & 69 & $2 \cdot 1$ & \\
\hline Premature gestation (< 37 weeks) & & & & & & & \\
\hline Yes & 405 & $6 \cdot 4$ & 196 & 6.4 & 209 & $6 \cdot 4$ & 0.97 \\
\hline No & 5931 & 93.5 & 2885 & 93.6 & 3066 & 93.6 & \\
\hline Low-birth weight $(<2500 \mathrm{~g})$ & & & & & & & \\
\hline Yes & 307 & $4 \cdot 1$ & 170 & $5 \cdot 6$ & 137 & $4 \cdot 2$ & 0.01 \\
\hline No & 6035 & $95 \cdot 2$ & 2893 & 94.4 & 3142 & $95 \cdot 8$ & \\
\hline Exact age at the 9-month interview (months) & & & & & & & \\
\hline $6 \cdot 0-7 \cdot 9$ & 223 & 3.5 & 109 & 3.6 & 114 & 3.5 & 0.83 \\
\hline $8.0-9.9$ & 5717 & $90 \cdot 1$ & 2766 & $90 \cdot 3$ & 2951 & $90 \cdot 0$ & \\
\hline $10 \cdot 0-12 \cdot 0$ & 403 & 6.4 & 189 & $6 \cdot 2$ & 214 & 6.5 & \\
\hline
\end{tabular}


Table 2. (Continued)

\begin{tabular}{|c|c|c|c|c|c|c|c|}
\hline \multirow{2}{*}{$\begin{array}{l}\text { Variables } \\
\text { Sex }\end{array}$} & \multicolumn{2}{|c|}{$\begin{array}{c}\text { All cohort } \\
n(\text { column \%) }\end{array}$} & \multicolumn{2}{|c|}{$\begin{array}{c}\text { Girls } \\
n \text { (column \%) }\end{array}$} & \multicolumn{2}{|c|}{$\begin{array}{c}\text { Boys } \\
n \text { (column \%) }\end{array}$} & \multirow[t]{2}{*}{$P^{\star}$} \\
\hline & & & & & & & \\
\hline Girls & 3064 & $48 \cdot 3$ & \multirow[t]{2}{*}{-} & & \multirow[t]{2}{*}{-} & & \multirow[t]{2}{*}{-} \\
\hline Boys & 3279 & $51 \cdot 7$ & & & & & \\
\hline \multicolumn{8}{|c|}{ Cohort children's weight status, screen time usage and demographics at the 54-month interview $(n$ 5596)\| } \\
\hline \multicolumn{8}{|c|}{ Screen time usage (average min/weekday) } \\
\hline$<60$ & 1070 & $19 \cdot 1$ & 543 & $20 \cdot 0$ & 527 & $18 \cdot 3$ & \multirow[t]{2}{*}{$0 \cdot 11$} \\
\hline$\geq 60$ & 4525 & $80 \cdot 9$ & 2172 & $80 \cdot 0$ & 2352 & $81 \cdot 7$ & \\
\hline \multicolumn{8}{|c|}{$\mathrm{BM}$ /age (WHO growth standard cut points) ${ }^{(26)}$} \\
\hline Underweight & 17 & $0 \cdot 3$ & $<10 \rrbracket$ & & 10 & 0.4 & \multirow{4}{*}{$<0.001$} \\
\hline Normal & 4745 & $85 \cdot 8$ & 2359 & $87 \cdot 8$ & 2386 & $84 \cdot 0$ & \\
\hline Overweight & 519 & $9 \cdot 4$ & 229 & 8.5 & 290 & $10 \cdot 2$ & \\
\hline Obesity & 249 & 4.5 & 93 & 3.5 & 156 & 5.5 & \\
\hline \multicolumn{8}{|c|}{ Waist circumference-to-height ratio (percentiles) } \\
\hline$\leq 90^{\text {th }}$ & 4953 & $90 \cdot 2$ & 2394 & 89.4 & 2559 & 90.9 & \multirow[t]{2}{*}{0.07} \\
\hline$>90^{\text {th }}$ & 540 & $9 \cdot 6$ & 283 & $10 \cdot 6$ & 257 & $9 \cdot 1$ & \\
\hline \multicolumn{8}{|c|}{ Exact age at the 54-month interview (months) } \\
\hline $48 \cdot 0-53 \cdot 9$ & 2563 & $45 \cdot 8$ & 1260 & $46 \cdot 4$ & 1303 & $45 \cdot 2$ & \multirow[t]{3}{*}{0.53} \\
\hline $54.00-59.9$ & 2971 & $53 \cdot 1$ & 1428 & $52 \cdot 6$ & 1543 & $53 \cdot 6$ & \\
\hline $60 \cdot 0-68.0$ & 62 & $1 \cdot 1$ & 27 & 1.0 & 35 & $1 \cdot 2$ & \\
\hline \multicolumn{8}{|l|}{ Sex } \\
\hline Girls & 2715 & $48 \cdot 5$ & & & & & \\
\hline Boys & 2881 & 51.5 & & & & & \\
\hline
\end{tabular}

NCEA, National Certificate of Educational Achievement; NZDep2006, neighbourhood deprivation index 2006; NZ, New Zealand.

Missing for variables listed in the table ( $n$ ): pregnancy planning (39); maternal education (26); maternal ethnicity (23); neighbourhood deprivation index (12); maternal age (10); parity (16); maternal length of time living in New Zealand (0); maternal BMI (739); maternal adherence to recommended intake of fruit and vegetables in pregnancy (542); maternal adherence to recommended intake of breads and cereals in pregnancy (542); maternal adherence to recommended intake of milk and milk products in pregnancy (542); maternal adherence to recommended intake of meats and alternatives and eggs in pregnancy (544); maternal smoking patterns (560); physical activity before/during pregnancy (542); age at the 9-month interview (0); sex (0); fetal count (0); gestational age $(<10 \eta)$; birth weight $(<10 \eta)$; age at the 54-month interview $((<10 \eta)$; screen time usage $(<10 \eta)$; BMI/ age (66); waist to height ratio (103).

${ }^{*} \chi^{2}$ tests for comparisons of proportions between girls and boys.

† Infants aged 6-12 months at the 9-month interview.

$\ddagger$ Derived from the 2006 national census according to the methodology described in Salmond et al.(22)

$\S$ Moderate/vigorous physical activity defined as engagement in moderate physical activity for at least 30 min for at least 5 out of $7 \mathrm{~d}$, or vigorous physical activity for at least 30 min on at least 2 out of $7 \mathrm{~d}$.

II Infants aged 6-12 months at the nine interview and who took part of the 54-month interview.

If As per Growing up in New Zealand study anonymity requirement, ' $<10$ ' represents greater than zero and less than ten children in the cell.

and health behaviour characteristics ( $R^{2}$ of the final model $=0 \cdot 291)$. The three maternal characteristics that had the strongest independent relationship with the IFI score, in the descending order of magnitude of associations, were: maternal age, level of education and smoking before and/or during pregnancy (Table 3).

\section{Associations between the infants' Infant Feeding Index scores with anthropometric indicators at the 54-month interview}

The proportion of children with overweight/obesity at the 54-month CAPI and the unadjusted associations between children's overweight/obesity and the covariates under study are presented in online Supplementary Tables S2 and S3. In the fully adjusted model including all children, the association between the IFI tertile and overweight/obesity was not statistically significant when compared with children who scored in the lowest tertile of the IFI with those who scored in the middle or highest tertiles. In the analysis stratified by sex, girls who scored in the lowest and middle tertiles were 56 and $46 \%$ more likely to be overweight/obese at the 54-month CAPI, respectively, compared with girls in the highest tertile. There was also a significant trend effect of lower adherence to the IFI and higher prevalence of overweight/obesity among girls (Table 4). Sensitivity analyses including girls with BMI-for-age outliers also identified similar statistically significant associations between overweight/obesity and the lowest IFI tertile compared with the highest IFI tertile (risk ratios $=1.48,95 \%$ CI 1.06, 2.08, $P=0.03$ ). This association was not statistically significant for the middle $v$. highest tertile of the IFI but approached statistical significance (risk ratios $=1.37,95 \%$ CI $0.98,1.90, P=0.06$ ) . There was no significant association between the IFI score and overweight/obesity among boys in the main analysis and in the sensitivity analysis (data not shown).

The proportion of children with WtHR greater than 90th centile at the 54-month CAPI and the unadjusted associations between children's WtHR and the covariates under study are presented in online Supplementary Tables S4 and S5. There were statistically significant associations between the IFI score and WtHR > 90th centile in the models including all the children and separately for boys. There was no significant association between the IFI score and WtHR > 90th centile for girls. Boys who scored in the first tertile of the IFI (compared with the third tertile) were $53 \%$ more likely to have central adiposity at the 54-month CAPI. A significant trend effect of lower adherence to the IFI and higher prevalence of central adiposity was also evident among boys (Table 4). 

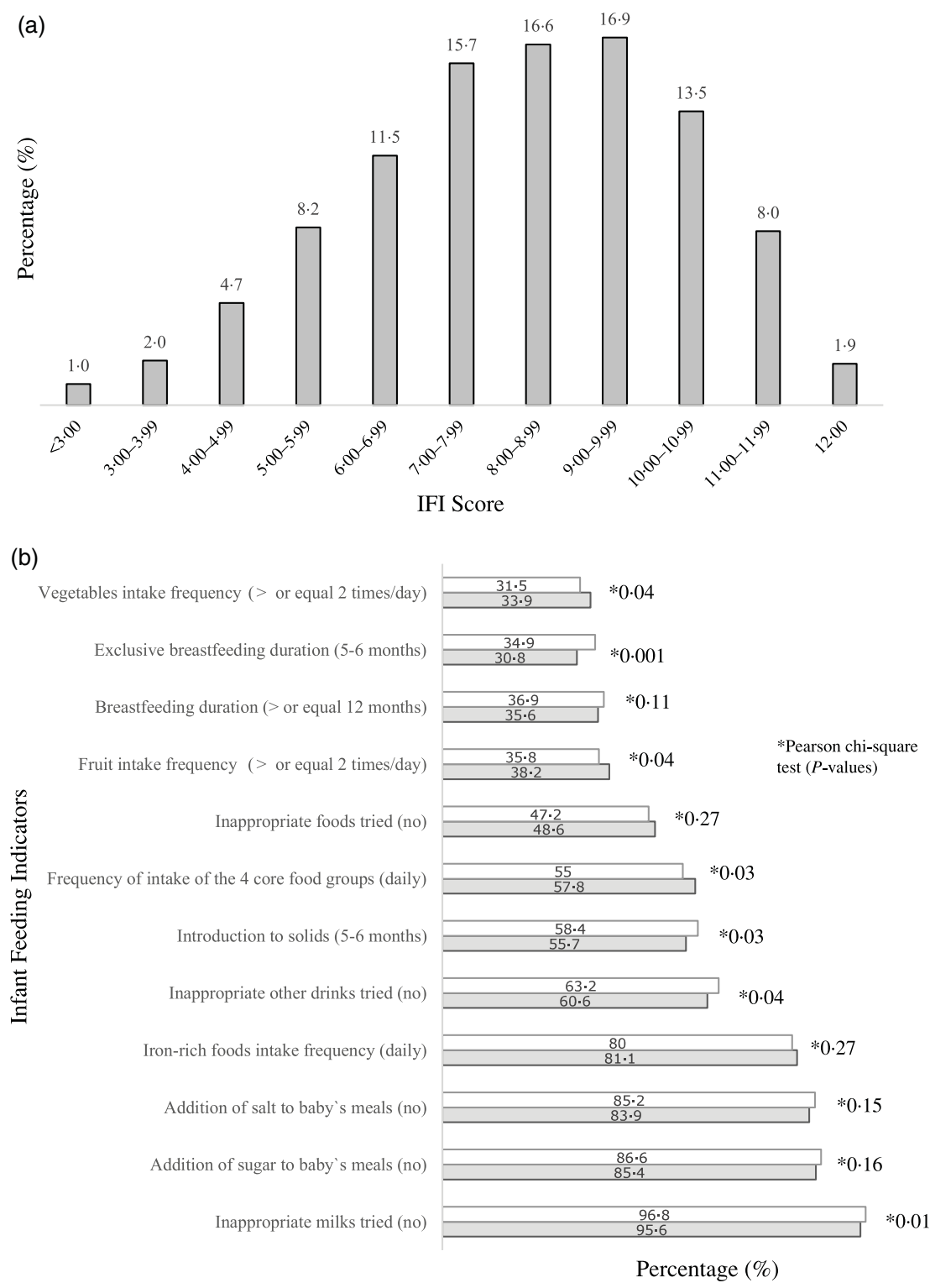

Fig. 1. Distribution of infants ( $n$ 6343) according to IFI score (a) and proportion of infants, by sex, who adhered to individual infant feeding indicators (b). Note: 6343 infants aged 6-12 months at the nine-month interview. IFI, Infant Feeding Index. Missing ( $n$ ): infant feeding index (193); duration of any breast-feeding (112); duration of exclusive breast-feeding (76); age of introduction to solids (31); eating across the four food groups daily (38); vegetables frequency of intake (28); fruit frequency of intake (30); Fe-rich foods frequency of intake (32); inappropriate milks (25); inappropriate other drinks (24); inappropriate foods (24); addition of salt to meals (25); addition of sugar to meals (25). *Pearson $\chi^{2}$ test $(P$-values). $\square$, girls; $\square$, boys

\section{Discussion}

\section{Statement of principal findings}

In this nationally generalisable cohort of children living in $\mathrm{NZ}$, there was poor adherence to national Infant Feeding Guidelines $^{(2)}$, with $15.9 \%$ of the cohort scoring less than six points in the IFI (which has a maximum score of twelve points). Adherence to the national Infant Feeding Guidelines ${ }^{(2)}$ had strong associations with maternal socio-demographic inequalities and health behaviours, which explained $30 \%$ of the variation in the IFI score. Lower IFI scores were associated with an increased likelihood of early childhood overweight/obesity and central adiposity, with sex differences evident. Compared with girls in the highest IFI tertile, girls in the lowest and middle tertiles were 46 and $56 \%$, respectively, more likely to be overweight/obese at the 54-month CAPI. Compared with boys in the highest IFI tertile, boys in the lowest tertile of the IFI were $53 \%$ more likely to have central adiposity at the 54-month CAPI. The associations between the IFI gradient score with maternal characteristics and with children's overweight/obesity and central adiposity were in the expected directions and confirm the IFI's convergent construct validity.

\section{Study findings in relation to other studies}

The poor adherence to Infant Feeding Guidelines verified in this study has been identified in many areas around the globe ${ }^{(39)}$. Data assessing individual infant feeding practices across eighty 
Table 3. Adjusted associations between the infant feeding index score and maternal socio-demographic and health behaviour characteristics (all cohort, $n 5146^{*}$ )

( $\beta$-coefficients and $95 \%$ confidence intervals)

\begin{tabular}{|c|c|c|c|}
\hline Antenatal maternal characteristics & Adj. $\beta \dagger$ & $95 \% \mathrm{Cl}$ & $P$ \\
\hline \multicolumn{4}{|l|}{ Pregnancy planning } \\
\hline Yes & 1.00 & & \\
\hline No & -0.40 & $-0.51,-0.28$ & $<0.001$ \\
\hline \multicolumn{4}{|l|}{ Highest level of education } \\
\hline Higher than bachelor's degree & 1.00 & & 0.42 \\
\hline Bachelor's degree & -0.06 & $-0.22,0.090$ & \\
\hline Diploma/trade cert/NCEA 5-6 & -0.78 & $-0.93,-0.62$ & $<0.001$ \\
\hline Secondary school/NCEA 1-4 & -0.64 & $-0.81,-0.48$ & $<0.001$ \\
\hline No secondary school qualification & $-1 \cdot 19$ & $-1.45,-0.93$ & $<0.001$ \\
\hline \multicolumn{4}{|l|}{ Self-prioritised ethnicity } \\
\hline European & 1.00 & & \\
\hline Māori & -0.91 & $-1.08,-0.74$ & $<0.001$ \\
\hline Pacific & -0.62 & $-0.80,-0.44$ & $<0.001$ \\
\hline Asian & -0.89 & $-1.07,-0.71$ & $<0.001$ \\
\hline MELAA and others & -0.46 & $-0.73,-0.18$ & 0.001 \\
\hline \multicolumn{4}{|l|}{$\begin{array}{l}\text { Neighbourhood deprivation } \\
\text { (NZDep2006 quintiles) } \ddagger\end{array}$} \\
\hline 1-2 least deprived & 1.00 & & \\
\hline $3-4$ & 0.02 & $0.15,0.18$ & 0.84 \\
\hline $5-6$ & -0.16 & $-0.33,0.01$ & 0.06 \\
\hline $7-8$ & -0.24 & $-0.41,-0.08$ & 0.004 \\
\hline 9-10 most deprived & -0.46 & $-0.63,-0.29$ & $<0.001$ \\
\hline \multicolumn{4}{|l|}{ Age group (years) } \\
\hline$\geq 35$ years & 1.00 & & \\
\hline $20-34$ years & -0.44 & $-0.55,-0.32$ & $<0.001$ \\
\hline$<20$ years & -1.39 & $-1 \cdot 66,-1 \cdot 11$ & $<0.001$ \\
\hline \multicolumn{4}{|l|}{ Parity } \\
\hline Subsequent & 1.00 & & \\
\hline First born & 0.20 & $0.09,0.30$ & $<0.001$ \\
\hline \multicolumn{4}{|l|}{ Length of time living in NZ (years) } \\
\hline Born in NZ & 1.00 & & \\
\hline Living in NZ for $>4$ years & 0.01 & $-0.13,0.15)$ & 0.85 \\
\hline Living in NZ for $\leq 4$ years & -0.37 & $-0.55,-0.19$ & $<0.001$ \\
\hline \multicolumn{4}{|l|}{$\mathrm{BMI}\left(\mathrm{kg} / \mathrm{m}^{2}\right)$} \\
\hline$<25.0$ & 1.00 & & \\
\hline $25-29.99$ & -0.19 & $-0.32,-0.07$ & 0.003 \\
\hline$\geq 30.0$ & -0.20 & $-0.34,-0.06$ & 0.005 \\
\hline \multicolumn{4}{|l|}{$\begin{array}{l}\text { Adherence to food and nutrition } \\
\text { guidelines in pregnancy - fruits } \\
\text { and vegetables }\end{array}$} \\
\hline Yes & 1.00 & & \\
\hline No & -0.26 & $-0.37,-0.15$ & $<0.001$ \\
\hline \multicolumn{4}{|l|}{$\begin{array}{l}\text { Adherence to food and nutrition } \\
\text { guidelines in pregnancy - breads } \\
\text { and cereals }\end{array}$} \\
\hline Yes & 1.00 & & \\
\hline No & 0.20 & $0.09,0.32$ & 0.001 \\
\hline \multicolumn{4}{|l|}{$\begin{array}{l}\text { Adherence to food and nutrition } \\
\text { guidelines in pregnancy - milk } \\
\text { and milk products }\end{array}$} \\
\hline Yes & 1.00 & & \\
\hline No & -0.20 & $-0.30,-0.10$ & $<0.001$ \\
\hline \multicolumn{4}{|l|}{ Smoking before and during pregnancy } \\
\hline $\begin{array}{l}\text { Non-smokers before and during } \\
\text { pregnancy }\end{array}$ & 1.00 & & \\
\hline Stopped smoking during pregnancy & -0.38 & $-0.55,-0.21$ & $<0.001$ \\
\hline Smokers before and during pregnancy & -1.03 & $-1.22,-0.84$ & $<0.001$ \\
\hline
\end{tabular}

Adj. $\beta$, adjusted $\beta$-coefficient; NCEA, National Certificate of Educational Achievement; NZDep2006, neighbourhood deprivation index 2006; NZ, New Zealand.

* Infants aged 6-12 months at the nine-month interview (excluded twins/triplets; babies born premature or with low-birth weight). Adjusted $R^{2}$ of multiple variable model $=0.291$.

† Average increase or decrease in the infant feeding index score in relation to the categories of reference.

‡ Derived from the 2006 national census according to the methodology described in Salmond et al. ${ }^{(22)}$ countries indicated that less than half of $0-5$-month-olds ( $42 \%$ ) were exclusively breastfed and that $43 \%$ of newborns were given liquids or foods other than breast milk within the first $3 \mathrm{~d}$ of life ${ }^{(39)}$. Our finding that less than $2 \%$ of the infants fully adhered to the overall Infant Feeding Guidelines are consistent with findings from the Avon Longitudinal Study of Parents and Children cohort (UK) study in which none of the infants were fully adherent to the overall guidelines (measured by the Complementary Feeding Utility Index $)^{(12)}$

In this study, approximately $30 \%$ of the variation in the IFI scoring was explained by antenatal maternal socio-demographic and health behaviour characteristics. The few studies that have assessed infant feeding practices using dietary indices have not investigated the contribution that maternal socio-demographic and health behaviours make to the whole infant feeding score variation $^{(5-9,12)}$. However, for comparison, the dietary index measuring adherence to Canadian dietary recommendations for 3 -year-old children found that socio-demographic characteristics explained approximately $6 \%$ of the index score variation ${ }^{(40)}$.

The associations of maternal socio-demographics and health behaviour characteristics with the IFI score were in the expected directions and corroborate findings of previous studies that social inequalities are an important influence on the overall feeding practices of young children ${ }^{(3,5,12,32)}$. Similar to our findings, older maternal age and high levels of education were the main predictors of a high score in the Complementary Feeding Utility Index among infants in the Avon Longitudinal Study of Parents and Children cohort ${ }^{(12)}$, and lower scores in the Complementary Feeding Utility Index were found among infants of mothers with pre-pregnancy BMI greater than $25 \mathrm{~kg} / \mathrm{m}^{2}$ or who smoked either before or during pregnancy. To date, there has been limited literature providing strong evidence of an association between the dietary quality of parents and their children ${ }^{(41,42)}$. Authors of a systematic review and metaanalysis concluded that there was weak resemblance between parents and children's diets, but acknowledged that among the twenty-four studies examined, most of them were based on small samples, about half were conducted in the USA and only two were based on national data ${ }^{(41)}$. A recent crosssectional study conducted in seventeen primary schools in Dunedin (NZ) found that parents scoring lower in a diet quality index score were more likely to have children with frequent consumption of confectionery, chocolate, cakes, biscuits and savoury snacks, but there was no association between parent and child fruit and vegetable intake ${ }^{(42)}$. Our study found that poor adherence to fruit, vegetable and dairy dietary guidelines during pregnancy was associated with low adherence to Infant Feeding Guidelines overall (after adjustment for confounders). The seemingly anomalous finding in our study that infants of mothers who adhered to the guideline of daily intake of breads and cereals had a lower IFI score could potentially be explained by the fact that the NZ dietary recommendations for pregnant women provide only minimum number of serving sizes for the four core food groups/daily ${ }^{(24)}$. Consequently, women consuming large quantities of breads and cereals (with potentially excessive energetic intake) would be classified as adhering to the guidelines along with women that have just 
Table 4. Adjusted associations between the infant feeding index score and the anthropometric outcomes at the 54-month interview (all cohort and by sex) (Risk ratios and $95 \%$ confidence intervals)

\begin{tabular}{|c|c|c|c|c|c|c|c|c|c|c|c|c|}
\hline \multirow{3}{*}{$\begin{array}{l}\text { Infant Feeding Index } \\
\text { score (tertiles) }\end{array}$} & \multicolumn{12}{|c|}{ Anthropometric outcomes at the 54-month interview } \\
\hline & \multicolumn{6}{|c|}{ BMI-for-age $>+2 z^{(26)}$} & \multicolumn{6}{|c|}{ WtHR $>$ p 90th } \\
\hline & Adjusted RR & $95 \% \mathrm{Cl})$ & $P^{\star}$ & Adjusted RR & $95 \% \mathrm{Cl}$ & $P^{\star}$ & Adjusted RR & $95 \% \mathrm{Cl}$ & $P^{*}$ & Adjusted RR & $95 \% \mathrm{Cl}$ & $P^{\star}$ \\
\hline & \multicolumn{3}{|c|}{ All cohort† $(n$ 4021) } & \multicolumn{3}{|c|}{ Girls $\ddagger(n$ 1973) } & \multicolumn{3}{|c|}{ All cohort§( $n$ 4020) } & \multicolumn{3}{|c|}{ Boys\|l(n 2530) } \\
\hline High & 1 (Ref) & & - & 1 (Ref) & & - & 1 (Ref) & & - & 1 (Ref) & & - \\
\hline Medium & 1.06 & $0.85,1.32$ & 0.61 & 1.46 & $1.03,2.06$ & 0.03 & 1.26 & $0.97,1.63$ & 0.08 & 1.27 & $0.86,1.86$ & 0.23 \\
\hline Low & 1.24 & $0.99,1.55$ & 0.06 & 1.56 & $1.09,2.23$ & 0.02 & 1.49 & $1.13,1.95$ & 0.04 & 1.53 & $1.02,2.30$ & 0.04 \\
\hline$P$-trend & 0.06 & & & 0.02 & & & 0.04 & & & 0.03 & & \\
\hline
\end{tabular}

RR, risk ratio; WtHR, waist-to-height ratio; $p$ 90th, ninetieth percentile; Ref, reference category.

${ }^{*}$ Wald test ( $P$-values).

† Excluded children with BMI-for-age $>+5 z$. Associations adjusted for child's sex, child's exact age and child's screen time usage at the 54-month interview, pregnancy planning; maternal self-prioritised ethnicity, antenatal maternal BMI, maternal adherence to recommended intake of breads and cereals in pregnancy and maternal smoking patterns.

$\ddagger$ Excluded girls with BMI-for-age $>+5$ z. Associations adjusted by child's exact age at the 54 -month interview, pregnancy planning, maternal self-prioritised ethnicity, maternal length of time living in New Zealand, antenatal maternal BMI, maternal adherence to recommended intake of breads and cereals in pregnancy and maternal smoking patterns.

$\S$ Associations adjusted for child's sex, maternal self-prioritised ethnicity, neighbourhood deprivation index, antenatal maternal BMI, maternal adherence to recommended intake of breads and cereals in pregnancy and maternal smoking patterns.

II Associations adjusted for maternal self-prioritised ethnicity, antenatal maternal BMI, maternal adherence to recommended intake of breads and cereals in pregnancy, maternal adherence to recommended intake of milk and milk products in pregnancy and maternal smoking patterns.

met the minimum cut-off for number of serves of breads and cereals daily.

Published evidence shows that childhood obesity is influenced by early life events and environmental factors, including diet ${ }^{(1,32,43,44)}$. However, despite this recognition association, the contribution of diet during infancy to the development of overweight/obesity remains relatively under explored ${ }^{(3,5)}$. Most of the previous studies that have investigated the effect of infant feeding on overweight/obesity later in life have focused on discrete infant feeding practices, for example, the effect of any/exclusive breast-feeding duration and age of food introduction $^{(37,38,45-47)}$. To date, the only other cohort study that has assessed the relationship of overall adherence to contemporary Infant Feeding Guidelines, using an index, with the development of childhood obesity, found no significant association with BMI and a weak association with WC at age 7 years, after adjustment for relevant socio-demographic confounders ${ }^{(13)}$. Systematic reviews show that, despite reported significant associations between early childhood dietary quality with later lean body mass, cognition and behaviour, the relationships reported with BMI and overweight/obesity have been null or weak ${ }^{(3,5)}$. Researchers argue that this may be due to the fact that the indices based on dietary guidelines may not adequately describe consumption patterns that are associated with chronic diseases/mortality, as well as the fact that the use of index scores may not reflect the risk gradients for major diet-related diseases ${ }^{(4)}$.

In $\mathrm{NZ}$, the prevalence of childhood obesity among children aged $2-14$ years increased from $8 \%$ in $2006 / 2007$ to $12 \%$ in $2017 / 2018^{(48)}$. In 2016, NZ had the second highest prevalence of overweight in 5-19-year-old children (39.5\%) among the countries of the European Union and Organization for Economic Co-operation and Development ${ }^{(39)}$. We identified an independent association between the degree of adherence to national Infant Feeding Guidelines and early childhood overweight/obesity and central obesity. The sex differences in the magnitude of associations between the score in the IFI and childhood overweight/obesity and central adiposity corroborate previously reported findings ${ }^{(49-51)}$. Studies have reported sex differences in the patterns of childhood adiposity and weight gain as well as in the patterns of factors associated with childhood obesity (including family environments, health behaviours, physiological markers and genetics) ${ }^{(49-51)}$. Another aspect to consider in our study is that, despite no statistically significant differences in the mean IFI score and IFI tertile distributions between girls and boys, there were sex differences in the adherence to some individual Infant Feeding Guideline components. Infant Feeding Guidelines represent a number of recommendations and some components may be more likely to influence child outcomes. However, currently, there is no evidence that allows us to measure the relative impact of each recommendation on child health outcomes to weight the indicators differently within the overall measurement of infant feeding practices $^{(12)}$.

\section{Strengths and weaknesses of the study}

NZ has little published information, nationally representative or generalisable, about infant feeding practices ${ }^{(14,20)}$. The routine data on breast-feeding and infant feeding collected by Lead Maternity Carers and Well Child Tamariki Ora providers in NZ are under-reported for the most disadvantaged groups of Māori and Pacific children ${ }^{(52)}$. There have been no previous studies in NZ on the determinants of whole-of-diet in the first year of life and the association of adherence to Infant Feeding Guidelines with the development of overweight/obesity during childhood. This investigation also adds to the international literature, as there are limited studies, especially in high-income countries, that have described dietary intakes of under 5-year-old children using a whole-of-diet measure ${ }^{(3,5,13)}$. To the best of our knowledge, this is the second longitudinal study to examine the influence that infant whole-of diet quality, based on contemporary guidelines, on later weight and WC during childhood, taking into account the influence of relevant maternal socio-demographic and health behaviours characteristics. In addition, by excluding preterm infants and those with low-birth weight from the analyses examining the 
association between the IFI and obesity, we removed circumstances where the Infant Feeding Guidelines and expected growth and development trajectories may not be applicable.

The main limitation of this study is that potentially important covariates associated with the development of childhood obesity may have not been included in the final multivariate models and, thus, the magnitude of the association between the IFI and obesity may be overestimated. Examples of covariates include objective infant PA and sleep measures which were not measured in the preschool years in this cohort, mode of delivery and antibiotic use, both recently reported as associated with child body size in this cohort ${ }^{(53,54)}$. The exclusion of children born with low-birth weight and preterm aimed to accounr for children more likely to have medical and developmental issues that may impcat feeding and growth. However, we have not accounted for other potential medical and developmental issues that may have affected infants' adherence to feeding guidelines and their body shape and composition through the first 5 years of life. Another notable limitation is that the IFI could only measure adherence to Ministry of Health guidelines that were able to be measured using the Growing Up in New Zealand data available, and therefore excluded indicators of increasing texture, variety and flavour of infant foods.

\section{Conclusions}

This research confirms the IFI's construct validity for future studies that will examine the influence of infant feeding practices on other subsequent dietary, health, behaviour and cognitive outcomes within the Growing up in New Zealand cohort.

This study's findings provide useful and nationally generalisable information that can be used to guide food and nutrition policies and interventions aiming at improving infant feeding practices. Appropriate nutrition in the first year of life is one of the internationally recommended approaches to reduce the double burden of malnutrition ${ }^{(1)}$. This study quantified relevant inequalities in infant feeding practices in NZ, many of which may be modifiable through improved maternal education, family income support, culturally relevant health promotion and access to prenatal health care which addresses health behaviours. The significant associations identified between adherence to national Infant Feeding Guidelines and childhood obesity/ central adiposity suggest that promoting adequate infant feeding practices in NZ constitutes a potential strategy to reduce childhood obesity.

\section{Acknowledgements}

The authors thank the participating families of the Growing Up in New Zealand cohort study who have given their time and shared the information that allowed us to conduct this research. The authors also thank the interviewers and researchers who designed, collected, cleaned and prepared the data for use. The Growing Up in New Zealand study has been designed and conducted by the Growing Up in New Zealand team, led by the University of Auckland. The authors would like to acknowledge the contributions of the original study investigators: Susan M. B. Morton, Polly E. Atatoa Carr, Cameron C. Grant,
Arier C. Lee, Dinusha K. Bandara, Jatender Mohal, Jennifer M. Kinloch, Johanna M. Schmidt, Mary R. Hedges, Vivienne C. Ivory, Te Kani R. Kingi, Renee Liang, Lana M. Perese, Elizabeth Peterson, Jan E. Pryor, Elaine Reese, Elizabeth M. Robinson, Karen E. Waldie, Clare R. Wall. The Growing up in New Zealand study has been funded by the New Zealand Ministries of Social Development, Health, Education and Justice; the former Ministry of Science Innovation and the former Department of Labour (now both part of the Ministry of Business, Innovation and Employment); the former Ministry of Pacific Island Affairs (now the Ministry for Pacific Peoples); the former Ministry of Women's Affairs (now the Ministry for Women); the Department of Corrections; the Families Commission (now known as the Social Policy Evaluation and Research Unit); Te Puni Kokiri; New Zealand Police; Sport New Zealand; Housing New Zealand Corporation; and the former Mental Health Commission (now part of the Office of the Health and Disability Commissioner); The University of Auckland and Auckland UniServices Limited. Other support for the study has been provided by the Health Research Council of New Zealand, Statistics New Zealand, the Office of the Children's Commissioner and the Office of Ethnic Affairs (now the Office of Ethnic Communities). The authors would also like to thank the Ministry of Health nutrition policy team, particularly Louise McIntyre, Anna Jackson and Elizabeth Aitken for providing advice on the selection of the indicators for the infant feeding index.

The Discipline of Nutrition and Dietetics (Faculty of Medical Sciences, University of Auckland, New Zealand) provided funding for analyses presented in this study.

T. G. C., S. G. and C. R. W. designed the objectives of the study. T. G. C. cleaned, merged and prepared the datasets. T. G. C. conducted the analysis, consulting with A. P. T. G. C., S. G., C. R. W., C. C. G., J. A. T., D. M. M. and S. M. B. M. contributed to the data interpretation. T. G. C., S. G. and C. R. W. drafted the manuscript. J. A. T., A. P., D. M. M., C. C. G. and S. M. B. M. revised the manuscript draft critically. All listed authors reviewed and approved the final version of the manuscript.

There are no conflicts of interest.

\section{Supplementary material}

For supplementary materials referred to in this article, please visit https://doi.org/10.1017/S0007114521001720

\section{References}

1. Hawkes C, Ruel M, Salm P, et al. (2020) Double-duty actions: seizing programme and policy opportunities to address malnutrition in all its forms. Lancet 395, 142-155.

2. Ministry of Health (2008) Food and Nutrition Guidelines for Healthy Infants and Toddlers (Aged 0-2): a Background Paper, 4th ed. Wellington: Ministry of Health.

3. Marshall S, Burrows T \& Collins CE (2014) Systematic review of diet quality indices and their associations with health-related outcomes in children and adolescents. J Hum Nutr Diet 27, 577-598.

4. Wajers PMCM, Feskens EJM \& Ocke MC (2007) A critical review of predefined diet quality scores. Br J Nutr 97, 219-231. 
5. Smithers LG, Gollwey RK, Brazionis L, et al. (2011) Characterizing whole diets of young children from developed countries and the association between diet and health: a systematic review. Nutr Rev 69, 449-467.

6. Ruel MT \& Menon P (2002) Child feeding practices are associated with child nutritional status in Latin America: innovative uses of the demographic and health surveys. J Nutr 132, 1180-1187.

7. Moursi MM, Martin-Prével Y, Eymard-Duvernay S, et al. (2008) Assessment of child feeding practices using a summary index: stability over time and association with child growth in urban Madagascar. Am J Clin Nutr 87, 1472.

8. Lohia N \& Udipi SA (2014) Infant and child feeding index reflects feeding practices, nutritional status of urban slum children. BMC Pediatr 14, 290.

9. Ma J-Q, Zhou L-L, Hu Y-Q, et al. (2012) A summary index of infant and child feeding practices is associated with child growth in urban Shanghai. BMC Public Health 12, 568.

10. Global Nutrition Report (2018) 2018 Global Nutrition Report. https://globalnutritionreport.org/reports/global-nutritionreport-2018/ (accessed August 2020).

11. World Health Organization \& the United Nations Children's Fund (2021) Indicators for Assessing Infant and Young Child Feeding Practices: definitions and Measurement Methods. Geneva: World Health Organization \& the United Nations Children's Fund.

12. Golley RK, Smithers LG, Mittinty MN, et al. (2012) An index measuring adherence to complementary feeding guidelines has convergent validity as a measure of infant diet quality. J Nutr 142, 901-908.

13. Golley RK, Smithers LG, Mittinty MN, et al. (2013) Diet quality of UK infants is associated with dietary, adiposity, cardiovascular, and cognitive outcomes measured at 7-8 years of age. $J$ Nutr 143, 1611-1617.

14. Castro TG, Gerritsen S, Wall C, et al. (2018) Infant Feeding in New Zealand: adherence to Food and Nutrition Guidelines among the Growing up in New Zealand Cohort. Wellington: Ministry of Social Development.

15. Morton SMB, Ramke J, Kinloch J, et al. (2015) Growing up in New Zealand cohort alignment with all New Zealand births. Aust N Z J Public Health 39, 82-87.

16. Bland JM \& Altman DG (2002) Validating scales and indexes (short note). BMJ 324, 606-607.

17. Chaltiel D, Adjibade M, Deschamps V, et al. (2019) Programme National Nutrition Sante- guidelines score 2 (PNNS-GS2): development and validation of a diet quality scores reflecting the 2017 French dietary guidelines. BJN 122, 331-342.

18. Morton SMB, Grant CC, Berry SD, et al. (2017) Growing Up in New Zealand: a Longitudinal Study of New Zealand Children and their Families. Now We Are Four: describing the Preschool Years. Auckland: Growing Up in New Zealand.

19. Marriott LD, Inskip HM, Borland SE, et al. (2009) What do babies eat? Evaluation of a food frequency questionnaire to assess the diets of infants aged 12 months. Public Health Nutr 12, 967-972.

20. Castro TG, Grant C, Wall C, et al. (2017) Breastfeeding indicators among a nationally representative multi-ethnic sample of New Zealand children. NZMJ 130, 34-44.

21. Wall CR, Brunt DR \& Grant CC (2009) Ethnic variance in iron status: is it related to dietary intake? Public Health Nutr 12, $1413-1421$.

22. Salmond C, Crampton P \& Atkinson J (2007) NZDep2006 Index of Deprivation. Wellington: University of Otago.

23. Statistics New Zealand (2005) Statistic Standard for Ethnicity Classification. Stats New Zealand. https://www.stats.govt.nz/ consultations/ethnicity-standard-classification-consultation (accessed August 2020).

24. Morton SMB, Grant CC, Wall CR, et al. (2014) Adherence to nutritional guidelines in pregnancy: evidence from the Growing Up in New Zealand birth cohort study. Public Health Nutr 17, 1919-1929.

25. World Health Organization (1995) Physical Status: the Use and Interpretation of Anthropometry. WHO Technical Report Series no 854. Geneva: WHO.

26. Craig CL, Marshall AL, Sjostrom M, et al. (2003) International physical activity questionnaire: 12-country reliability and validity. Med Sci Sports Exerc 35, 1381-1395.

27. Ministry of Health (2008) Protocol for Collecting Height, Weight and Waist Measurements in New Zealand Health Monitor (NZHM) Surveys. Wellington: Ministry of Health.

28. World Health Organization (2006) WHO Child Growth Standards: Length/Height-for-Age, Weight-for-Age, Weightfor-Length, Weight-for-Height and Body Mass Index-for-Age: Methods and Development. Geneva: WHO.

29. World Health Organization (2019) Guidelines on Physical Activity, Sedentary Behaviour and Sleep for Children under 5 Years of Age. Geneva: WHO.

30. Barros AJ \& Hirakata VN (2003) Alternatives for logistic regression in cross-sectional studies: an empirical comparison of models that directly estimate the prevalence ratio. BMC Med Res Methodol 3, 21.

31. Zou GA (2004) Modified Poisson regression approach to prospective studies with binary data. Am J Epidemiol 159, 702-706.

32. Baidal JAW, Locks LM, Cheng ER, et al (2016) Risk factors for childhood obesity in the first 1000 d. Am J Prev Med 50, 761-799.

33. Magalhaes EIS, Sousa BA, Lima NP, et al. (2019) Maternal smoking during pregnancy and offspring body mass index and overweight: a systematic review and meta-analysis. Cad Saude Publica 35, e00176118.

34. Shackleton N, Derraik JGB, Audas R, et al. (2019) Decomposing ethnic differences in body mass index and obesity rates among New Zealand pre-schoolers. Int J Obes 43, 1951-1960.

35. Agsbota G, Fievet N, Heude B, et al. (2019) Poor maternal anthropometric status before conception is associated with a deleterious infant growth during the first year of life: a longitudinal pre-conceptional cohort. Pediatr Obes 15, e12573.

36. Stiglic N \& Viner RM (2019) Effects of screen time on the health and well-being of children and adolescents: a systematic review of reviews. BMJ Open $\mathbf{9}$, e023191.

37. Meyerkort CE, Oddy WH, O'Sullivan TA, et al. (2011) Early diet quality in a longitudinal study of Australian children: associations with nutrition and body mass index later in childhood and adolescence. J Develop Origins Health Dis 3, 21-31.

38. Robinson SM, Marriott LD, Crozier SR, et al. (2009) Variations in infant feeding practice is associated with body composition in childhood: a prospective cohort study. J Clin Endocrinol Metab 94, 2799-2805.

39. United Nation Children's Fund (2019) The State of the World's Children 2019. Children, Food and Nutrition: growing well in a Changing World. New York: UNICEF.

40. Jarman M, Vashi N, Angus A, et al. (2020) Development of a diet quality index to assess adherence to Canadian dietary recommendations in 3-year-old children. Public Health Nutr 23, 385-393.

41. Wang Y, Beydoun MA, Li J, et al. (2011) Do children and their parents eat a similar diet? Resemblance in child and parental dietary intake: systematic review and meta-analysis. J Epidemiol Community Health 65, 177-189. 
42. Davison B, Saeedi P, Black K, et al. (2017) The association between parent diet quality and child dietary patterns in nine- to eleven-year-old children from Dunedin, New Zealand. Nutrients $\mathbf{9}, 483$.

43. World Health Organization (2016) Report of the Commission on Ending Childhood Obesity. Geneva: WHO

44. Mikkelsen B, Williams J, Rakovac I, et al. (2019) Life-course approach to prevention and control of non-communicable diseases. Br Med J 364, 1257.

45. English LK, Obbagy JE, Wong YP, et al. (2019) Timing of introduction of complementary foods and beverages and growth, size, and body composition: a systematic review. Am J Clin Nutr 109, 935S-955S.

46. Gibson LA, Alava MH, Kelly MP, et al. (2017) The effects of breastfeeding on childhood BMI: a propensity score matching approach. J Public Health 39, e152-e160.

47. Sirkka O, Vrijkotte T, Halberstadt J, et al. (2018) Prospective associations of age at complementary feeding and exclusive breastfeeding duration with body mass index at 5-6 years within different risk groups. Pediatr Obes 13, 522-529.
48. Ministry of Health (2019) 2019 New Zealand health statistics. https://www.health.govt.nz/nz-health-statistics/health-statisticsand-data-sets/obesity-statistics (accessed August 2020).

49. Anderson SE \& Whitaker RC (2018) Association of selfregulation with obesity in boys vs girls in a US national sample. JAMA Pediatr 172, 842-850.

50. Govindan M, Gurm R, Mohan S, et al. (2013) Gender differences in physiologic markers and health behaviors associated with childhood obesity. Pediatrics 132, 468-474.

51. Sweeting HN (2008) Gendered dimensions of obesity in childhood and adolescence. Nutr J 7, 1.

52. Ministry of Health (2013) The Health Status of Children and Young People in New Zealand. Dunedin: New Zealand Ministry of Health.

53. Makasume G, Mccarthy FP, Russell J, et al. (2019) Caesarean section delivery and childhood obesity: evidence from the Growing up in New Zealand cohort. J Epidemiol 73, 1063-1070.

54. Chelimo C, Camargo CA, Morton SMB, et al. (2020) Association of repeated exposure up to age 4 years with body mass and age 4.5 years. JAMA Netw Open 3, e1917577. 